\title{
LA «LETANÍA DE NUESTRO SEÑOR DON QUIJOTE»
}

\author{
JosÉ CARLOS ROVIRA \\ Universidad de Alicante
}

\section{Resumen}

En 1905 escribe Rubén Darío la «Letanía de nuestro señor don Quijote» que se integra en Cantos de vida y esperanza. Se trata de una de las conmemoraciones cervantinas más importantes del año del centenario de la publicación de la primera parte del Quijote, por las resonancias culturales y sociales que se identifican en ese texto que es la culminación de una larga trayectoria cervantina del poeta. Comentar el poema en sus referencias culturales y en su oposición a aspectos de la conmemoración popular y sobre todo de confrontación con la celebración académica es el objetivo de la lectura que proponemos.

Palabras clave: Darío, Centenario, Conmemoración, Don Quijote, Academias.

\begin{abstract}
On 1905 Rubén Darío writes the «Letanía de nuestro señor Don Quijote», a long poem that later would be included in Cantos de vida y esperanza. It was the Centenary of the publication of the first part of Don Quixote, and, due to the cultural and social echoes found in the text, it was one of the most important tributes to Cervantes of that year. The main goal of our work is to discuss the poem from the perspective of its various cultural references and its antagonism towards academic and popular celebrations.
\end{abstract}

Keywords: Dario, Centenary, Commemoration, Don Quijote, Academies. 
En Febrero de 1905 vuelve Rubén Darío a España. El poeta, con treinta y ocho años sólo, estaba físicamente destrozado por el alcohol. Pero se aprestaba a una presencia española definitiva que tuvo en julio el momento culminante con la publicación de Cantos de vida y esperanza ${ }^{1}$.

\section{Una extraña afirmación de Juan Ramón Jiménez}

Jiménez nos da datos en Mi Rubén Darío que conciernen a la escritura de la obra esencial que publica ese año y al tema cervantino en Darío a propósito de su estancia en Madrid en 1905, cuando describe su vivienda de calle de las Veneras: «En el fondo de la alcoba estaba la cama y en la parte del balcón un escritorio, una mesa "ministro" sin más que un ejemplar del Quijote, que en aquel momento leía con gran entusiasmo, quizá por primera vez...» (Jiménez, 1990: 138). La frase final no aparece justificada ni creo que sea justificable porque, según varios biógrafos, Darío viajó siempre con una Biblia, un libro de mitología y un ejemplar del Quijote. Y en La vida de Rubén Darío escrita por él mismo nos dice que fue desde luego una primera lectura de juventud.

\section{La larga trayectoria cervantina de Darío}

Hay dos poemas de Cantos de vida y esperanza que tienen un motivo, el cervantino, de larga trayectoria en Darío, quien en su primer libro, Epístolas y poemas (aparecido en 1888, el mismo año que Azul, pero impreso y no difundido desde 1885 con el título de Primeras notas) publicó una extensa «Epístola a Juan Montalvo» que había aparecido en El Ferro-carril de Managua el 19 de julio de 1884. El ecuatoriano Montalvo, a pesar de la lejanía, era maestro para Darío desde la casi infancia en León, donde había un grupo de intelectuales devotos del autor de Napoleón y Bolívar y sobre todo de los capítulos editados en prensa de lo que en 1895, y póstuma, se llamará Capítulos que se le olvidaron a Cervantes. A través de su lectura temprana, Darío conoce desde luego el prólogo, «El buscapié», quizá la mejor parte de la obra, y reflexiona en su poema sobre aquella inmersión e invención de capítulos del Quijote con un sentido profundamente americano, destacando su bolivarismo y su quijotismo. Montalvo ha fundido por primera vez, nos dice Darío en su epístola, un mito de la libertad americana, con un mito de la libertad universal como

1. No reitero aquí lógicamente todo lo que dije en mi edición y amplio comentario de esta obra: Rubén Darío, Cantos de vida y esperanza, ed. de José Carlos Rovira, Madrid, Alianza, 2004. Las citas de textos proceden de esta edición o de Darío, 2011 (edición de la Obra poética). 
Cervantes. Transita Darío por esta fusión como alabanza y como propósito futuro e inaugura desde luego con ella su cervantismo duradero.

Conocemos perfectamente el apoyo de Darío al proceso independentista cubano, pero en 1898 ha constatado la tergiversación de la historia anunciada que los Estados Unidos han realizado. Escribe un relato, un texto bastante desconocido que se publico en el año 1899 en el Almanaque Peuser de Buenos Aires. Se trata de un cuento que, como título, lleva las siglas «D.Q.»: una metáfora del Quijote ensamblada a la guerra de España en Cuba y a la sucesión del dominio por los Estados Unidos, en la que Darío hace al héroe cervantino protagonista español de aquella guerra (Darío, 2002: 143-159).

Hay además otros textos vinculados al motivo: «Hércules y don Quijote»; «En tierra de don Quijote»; «La cuna del manco»; una referencia esencial en «El triunfo de Calibán» (cf. Valero, 2008: 143-159).

\section{Darío y su conmemoración en 1905}

Hay un texto que considero esencial para la conmemoración dariana de 1905. Se trata por supuesto de la «Letanía de Nuestro Señor Don Quijote», que Darío debía haber leído en el homenaje realizado por el Ateneo de Madrid a Cervantes, en un acto organizado en el Pananinfo de la Universidad Central. Mejía Sánchez sigue siendo la referencia principal para la publicación y la lectura de la obra: «escrita especialmente por Darío para el homenaje a Cervantes en el III Centenario de la publicación del Quijote, organizado por el Ateneo de Madrid en el Paraninfo de la Universidad, 13 de mayo de 1905. Vargas Vila pretende que la «letanía», por enfermedad de Darío, fue leída por Gregorio Martínez Sierra, comisionado por Darío al efecto. El impreso del Ateneo (Madrid, mayo de 1905, Imprenta de Bernardo Rodríguez), que contiene las conferencias y poesías pronunciadas en la ocasión, en una nota al texto [...] dice: «Esta poesía y la de Fernando A. de Icaza, fueron magistralmente leídas por Ricardo Calvo» (Mejía, 1985: LXXIII). Está dedicado «A [Francisco] Navarro Ledesma», cervantista y autor de El ingenioso hidalgo Miguel de Cervantes Saavedra, cuya influencia fue muy grande en autores como José Ortega y Gasset.

El poema lo forman setenta y cinco versos cuya base métrica son sextetos agudos en dodecasílabos polirrítmicos con rima consonante $\mathrm{AAB}^{\prime} \mathrm{CCB}^{\prime}$, con excepciones en la novena y décima estrofa (donde la base versal son hexasílabos). La métrica de Darío es la más compleja de nuestra tradición en sus recuperaciones. Tomás Navarro Tomás decía que «en ningún poeta francés, parnasiano o simbolista, se registra un repertorio de metros y estrofas tan extenso como el que Rubén Darío practicó» (Navarro Tomás, 1974: 31). 
Comentó Darío: «La Letanía de Nuestro Señor don Quijote afirma otra vez mi arraigado idealismo, mi pasión por lo elevado y heroico. La figura del caballero simbólico está coronada de luz y de tristeza. En el poema se intenta la sonrisa del «humour» — como un recuerdo de la portentosa creación cervantina-, mas tras el sonreír está el rostro de la humana tortura ante las realidades que no tocan la complexión y el pellejo de Sancho» (Darío, 1988: 99).

\section{Referencias culturales}

Es necesaria una aproximación al poema que ha llamado «Letanía»: como sabemos es una «oración cristiana que se hace invocando a Jesucristo, a la Virgen o a los santos como mediadores, en una enumeración ordenada», según el diccionario académico. El modelo principal, las Letanías lauretanas, crean una construcción bimembre, paralelística y reiterativa:
Sancta María.
Ora pro nobis
Sancta Dei Génetrix.
Ora pro nobis
Sancta Virgo Vírginum.
Ora pro nobis
Mater Christi.
Mater Ecclesiae.
Ora pro nobis
Ora pro nobis;

recordada explícitamente en su invocación aquí al Quijote:

Rey de los hidalgos, señor de los tristes,

[...]

¡Ruega por nosotros, hambrientos de vida,

con el alma a tientas, con la fe perdida,

llenos de congojas y faltos de sol,

por advenedizas almas de manga ancha,

que ridiculizan el ser de la Mancha,

el ser generoso y el ser español!

¡Ruega por nosotros, que necesitamos

las mágicas rosas, los sublimes ramos

de laurel! Pro nobis ora, gran señor (vv.1 y vv. 32-40).

Siguen una serie de referencias culturales precisas que van dando densidad al poema; así, los versos 25-28:

...y, teniendo a Orfeo, tienes a orfeón!

Escucha, divino Rolando del sueño,

a un enamorado de tu Clavileño,

y cuyo Pegaso relincha hacia ti;

comienzan con un juego esencial, una paradoja, en la que la palabra raíz de orfeón, la que posee don Quijote, Orfeo, el divino poeta y músico clásico educador de los seres humanos con su canto, se ve sustituido (luego veremos 
contextualmente el porqué) por el canto celebrativo y conmemorativo; sigue Rolando «del sueño», donde el héroe medieval del poema francés del siglo XII (La chanson de Roland) se convierte en ensoñación épica; Clavileño es la referencia al capítulo XLI de la segunda parte del Quijote, utilizado otras veces como en «Cyrano en España» (poema V de la primera parte de Cantos de vida y esperanza) como recurso referencial al caballo de madera que, repleto de fuegos de artificio, hará volar a don Quijote; Pegaso, el caballo alado nacido de la sangre de Medusa, es para Darío símbolo personal de la energía espiritual y de la creación, del carácter mítico y divino de la misma.

Siguen referencias importantes en los versos 42 y 43 ( «y antes que tu hermano vago, Segismundo, / el pálido Hamlet te ofrece una flor»), donde el protagonista calderoniano y el shakespereano se unen (como en el poema «Al rey Óscar», III de Cantos de vida y esperanza) en homenaje al héroe cervantino.

La referencia a Nietzsche y a su teoría del superhombre en el verso 51, $\tan$ frecuente desde la literatura finisecular europea y española, es rechazada explícitamente en una serie versal que luego comentaremos.

Términos como «malsines» del verso 56 (los que hablan mal de otros, los delatores o detractores que utilizan la falsedad); el neologismo «canallocracia» («Gobierno de los canallas») del verso 60, que es una palabra que no estaba en los diccionarios, aunque sí en el lenguaje periodístico, son resaltables en cuanto cumplen la dinámica de descripción de la sociedad que también pretende el poeta.

\section{En busca de cuadros}

La sección «En busca de cuadros» de Azul, cuando el poeta Ricardo sube a un cerro de Valparaíso buscando imágenes naturales para sus cuadros, marca una atención inicial y siempre vigente en Darío para construir su poesía y sus poemas-paisaje. Lo he estudiado recientemente en «Rubén Darío: geografía, pintura y paisajes» (Rovira: 2016: 131-158) y planteo ahora, al margen de naturalezas, las figuras culturales que llamaron la atención desde su llegada a España en 1989, en aquellas prosas que forman España contemporánea (Darío, 2017) en las que exposiciones, galerías y pinturas forman parte de los recorridos principales del poeta para hacer también crónica del país.

La figura del ingenioso hidalgo tenía que ser búsqueda principal entre sus objetivos. Conoce desde luego Darío una tradición pictórica europea, sobre todo francesa, que compara con lo que va encontrado en la pintura española: Jean Mosnier, quien entre1625 y 1634 pinta en el comedor y la antesala del castillo de Cheverny, en el Loire, una interesante versión de escenas del 


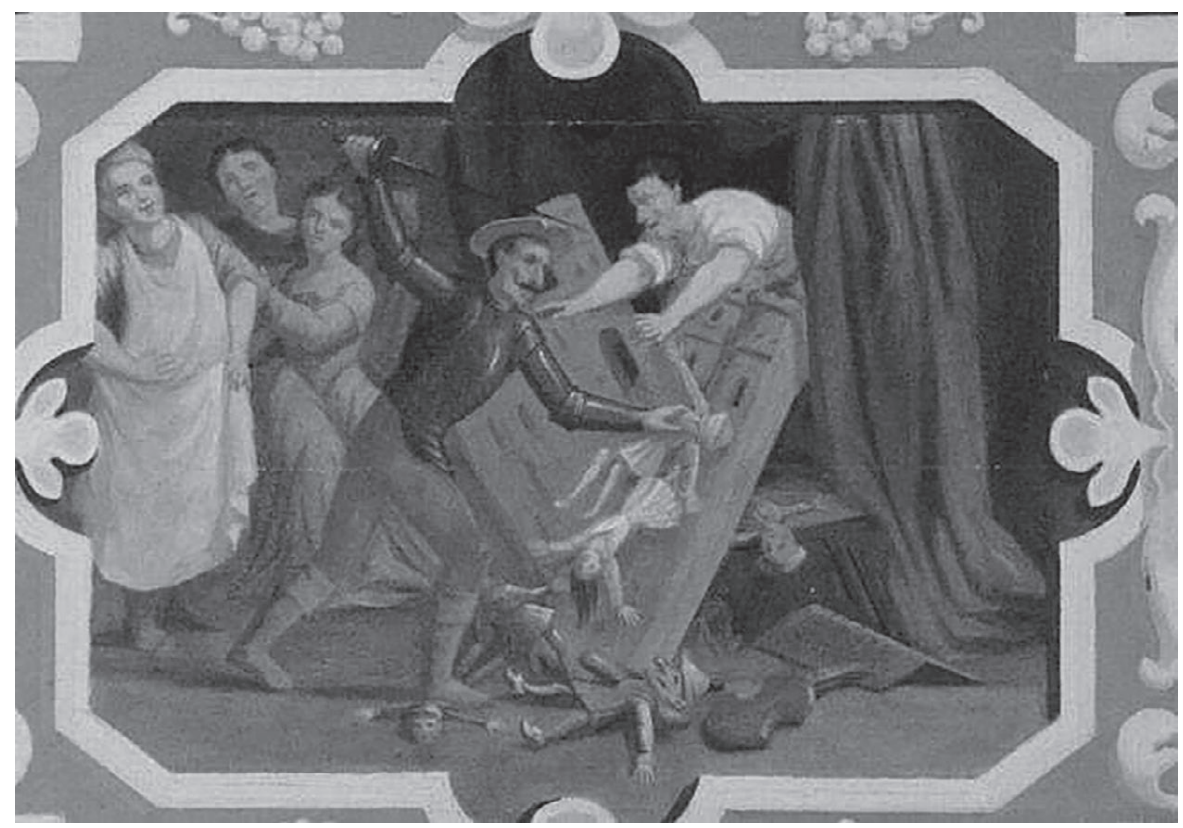

Jean Monsier: Retablo de Maese Pedro.

Quijote, entre ellas las de el acuchillamiento de los muñecos de madera en el retablo de Maese Pedro (Darío, 2017: 136).

Sigue luego citando a pintores dieciochescos como Charles Coypel y su serie historial sobre el personaje y episodios de la obra, en la que destaca su «Don Quijote servido por las damas de la posada».

Siguen referencias a otros neoclásicos como Jean-Baptiste Pater, CharlesJoseph Natoire, Pierre Charles Tremoliére y llegando ya a la pintura del XIX, François Boucher, hasta citar a pintores ingleses contemporáneos a él mismo como Frank Brangwyn. Sobre ellos nos dice que «pocos, sin embargo, han logrado ser visitados por el verdadero espíritu de Cervantes» (Darío,1917:136).

José Moreno Carbonero es al primero que descubre y el que más le llama la atención. De hecho es un pintor que está triunfando: y «su amor por el Quijote es conocido» (Darío,1917 : 33). Moreno busca en sus cuadros quijotescos la realidad y la consigue: «nos decía que andaba en busca de un tipo campesino que tuviese la figura del Sancho que él se imagina; y que creía haberla encontrado en un bausán manchego que había visto, como para ser reconocido por Teresa, Sanchica y el rucio» (ibíd.). 
La realidad esta conseguida, nos dice Darío, y nos cita otra escena de Moreno Carbonero como es la de la aventura con el vizcaíno, cuya imagen responde a la siguiente representación.

Comenta luego otra serie de ilustraciones cervantinas de José Jiménez Aranda: «muy notables como dibujo, pero que no tienen nada de personajes cervantescos; esos Quijotes y esos Sanchos son un Juan y un Pedro de cualquier parte, vestidos para representar un papel» (ibid. 136), para hacer una serie de afirmaciones que tienen que ver con la imposición de la realidad porque «no hay que olvidar que Don Quijote es la caricatura del ideal; pero siempre en un ambiente de ideal», y finalmente «tanta realidad hace daño a la idealidad del tipo, a lo, por decir así, grotesco angélico que hay en el héroe que Cervantes creara con tanto amor y amargura» (ibid. 136).

Quizá toda la reflexión sobre la pintura quijotesca, que debía se idealidad, hay que sintetizarla como imagen concentrada en aquel fragmento de la Letanía en el que don Quijote alienta fuerzas, viste ensueños, se corona de ilusión,

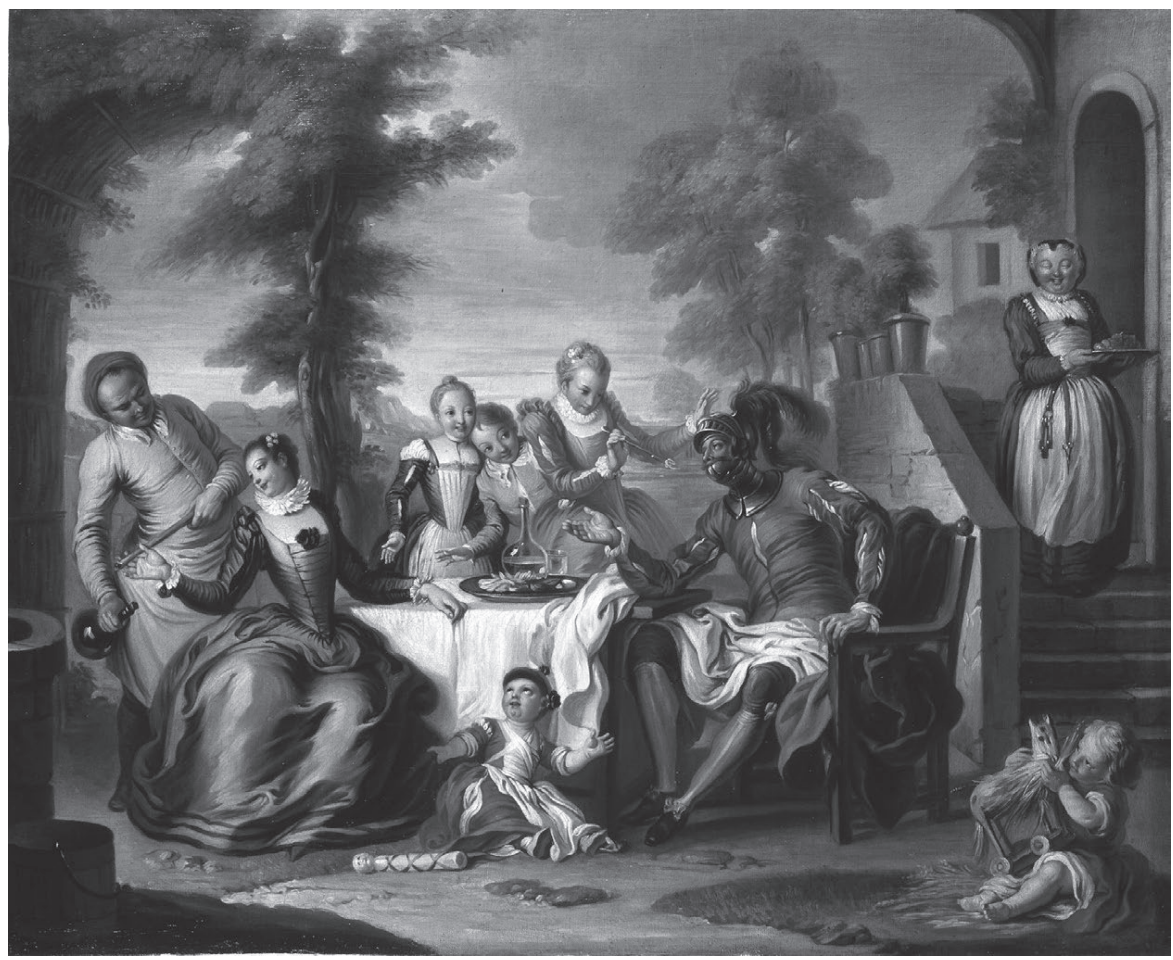

Charles Coypel: Don Quijote servido por las damas de la posada.

Anales, 28 (2016), pp. 237-249 


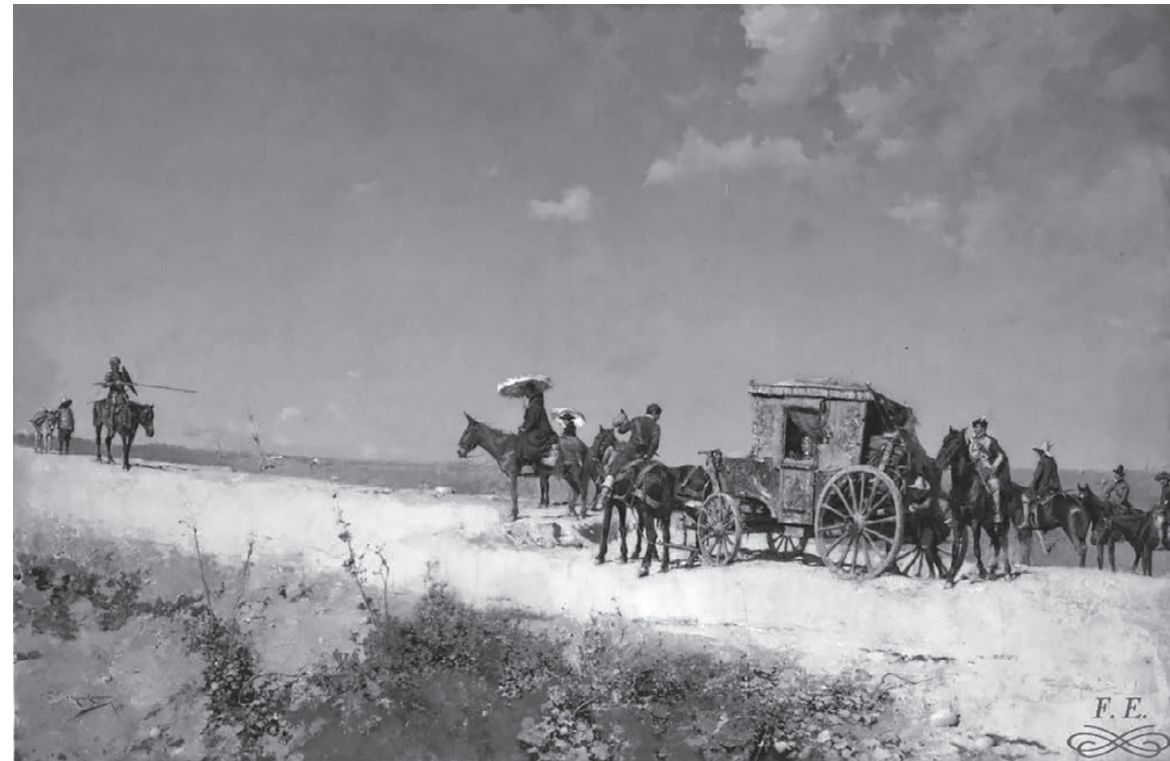

Moreno Carbonero: La aventura del vizcaíno.

con su adarga que es fantasía y la lanza que es corazón, con heroicidad que se desenvuelve igual entre contrarios en la antítesis final:

Rey de los hidalgos, señor de los tristes, que de fuerza alientas y de ensueños vistes, coronado de áureo yelmo de ilusión; que nadie ha podido vencer todavía, por la adarga al brazo, toda fantasía, y la lanza en ristre, toda corazón.

Noble peregrino de los peregrinos, que santificaste todos los caminos con el paso augusto de tu heroicidad contra las certezas, contra las conciencias y contra las leyes y contra las ciencias, contra la mentira, contra la verdad... (vv. 1-12).

Quiero decir que la amplia indagación visual sobre la figura pictórica del Quijote se resuelve en la palabra que intenta definirlo en la Letanía. Darío ha intentado definir aquí, en los versos que citaba, la idealidad que no encuentra en sus representaciones. 


\section{La conmemoración popular}

España celebraba popularmente el III Centenario del Quijote. Fue moda poner en casi todos los ayuntamientos placas conmemorativas. Los municipios cervantinos celebraban más que nadie la efemérides: Alcázar de San Juan por ejemplo, en su disputa por ser la cuna del manco, inauguraba en los días 14 y 15 de mayo los «Festejos en honor de Cervantes», con dianas de las bandas de música de todo el Campo de Criptana, discursos ante la pila bautismal, gran cabalgata, fuegos artificiales, himnos infantiles a Cervantes, obsequios a lo pobres «siempre que lo recaudado por la Comisión de festejos lo permita», según dice el programa; retretas e iluminaciones de las calles. Muchas ciudades tienen conmemoraciones del mismo tipo, resumibles en el manifiesto de la conmemoración de Alcázar:

Alcazareños: España, el mundo entero, celebra la fecha gloriosa de la aparición de aquel libro inmortal, sobre el que en vano pasan lo siglos pues es eternamente joven [...] Alcazareños: unámonos todos en tan fausto día, y a una voz exclamemos. ¡Viva Cervantes! ¡Gloria al Quijote! (Tercer centenario del Quijote de la Mancha / Alcázar).

No hay duda que es este contexto social el que nos permite leer los siguientes versos de la Letanía:

¡Caballero errante de los caballeros, barón de varones, príncipe de fieros, par entre los pares, maestro, salud!

¡Salud, porque juzgo que hoy muy poca tienes, entre los aplausos o entre los desdenes, y entre las coronas y los parabienes y las tonterías de la multitud!

¡Tú, para quien pocas fueran las victorias antiguas y para quien clásicas glorias serían apenas de ley y razón, soportas elogios, memorias, discursos, resistes certámenes, tarjetas, concursos, y, teniendo a Orfeo, tienes a orfeón! (vv.13-25).

\section{La conmemoración culta y académica}

Al margen de este tipo de conmemoraciones populares, el Quijote obtuvo una conmemoración reflexiva y culta: Azorín, con La ruta de don Quijote; Unamuno, con Vida de don Quijote y Sancho, o múltiples aspectos de la visión concentrados en la psicología del quijote (Ramón y Cajal) o el pensamiento 
español (Bonilla y San Martín), o la continuidad de las visiones esotéricas de Nicolás Díaz de Benjumea algunos años antes y secundadas en el centenario.

La conmemoración académica se celebró el 8 de mayo en una sesión solemne presidida por el Rey. La Academia había encargado el discurso para la ocasión a Juan Valera, que falleció el 18 de abril, por lo que el discurso, brillante, riguroso y ponderado, fue leído por el académico Alejandro Pidal y Mon, quien apostilla al final, tras señalar la muerte del autor, que:

Hasta aquí llega el discurso del Sr. Valera. Aquí cortó con implacable tijera, la dura mano de la Parca, el doble hilo de oro del discurso y de la vida del escritor, consagrando con el rapto violento de su personalidad y su tránsito al mundo de las realidades eternas y de los destinos realizados, el juicio definitivo y perfecto de una larga vida de estudio sobre la obra maestra que nos envidia y celebra a la vez, asombrado y regocijado el mundo de las opiniones opuestas y de las disputas irreductibles, que al saludar al Quijote con el rendido homenaje de su unánime admiración, no se da suficiente y acabada cuenta tal vez, de que saluda en él no sólo al monumento literario erguido como una pirámide colosal, insumergible en el diluvio de la publicidad contemporánea; no sólo al portentoso genio creador de las dos imperecederas figuras en que se reconoce personificada la humanidad, sino al pueblo que cooperó a su creación suministrando la rica sangre de sus venas para darlas vida y calor, y lo más puro de su alma, para informarlas con el espíritu caballeresco y cristiano que brilla con inextinguibles destellos de nobleza y generosidad hasta en los rasgos más burlescos de sus inmortales aventuras.

Porque todo se podrá armonizar en síntesis más o menos alambicadas y confusas, menos la perenne y cada vez más entusiasta admiración por el Quijote, y el menosprecio constante hacia la patria de su autor y hacia el ideal luminoso que lo inspira y que lo agiganta y que tan heroicamente realizó en la Historia aquella gran democracia cristiana que se llamó el Pueblo Español, y que si por haberse apartado de él perdió el privilegio de que el Sol no se pusiese nunca en sus dominios, contempla todavía con amor y satisfacción que ningún error ni ninguna deformidad pasajeramente triunfantes han logrado conseguir que el glorioso libro español que lo cifra y que lo consagra se ponga en los dominios civilizados del orbe, como astro de viva y radiante luz que alumbra y que regocija a la Tierra (Valera/Pidal, 1905).

El largo párrafo del Marqués de Pidal es fruto sin duda de su debilidad conservadora, de su esencial conversión en un valor para la patria acosada del discurso conmemorativo cervantino, realizado por Juan Valera, sobre quien advierte que «no se da suficiente y acabada cuenta tal vez» de que el Quijote es el discurso de un pueblo que sufre "el menosprecio constante hacia la patria de su autor y hacia el ideal luminoso que lo inspira y que lo agiganta y que tan heroicamente realizó en la Historia aquella gran democracia cristiana que se llamó el Pueblo Español, y que si por haberse apartado de él perdió el 
privilegio de que el Sol no se pusiese nunca en sus dominios». Darío habría participado de estas reflexiones en aras de su visión de la hispanidad acosada, sino fuera que en ese momento tenía otras cosas que decir, conmemorativamente también, pero probablemente en otra línea de expresión.

Sin duda a ella responden los versos:

De tantas tristezas, de dolores tantos,

de los superhombres de Nietzsche, de cantos

áfonos, recetas que firma un doctor,

de las epidemias de horribles blasfemias

de las Academias,

líbranos, señor (vv. 50-55).

Ha creado además un momento clave del poema para el contexto cultural como son los versos 53-55: «de las epidemias, de horribles blasfemias / de las Academias, / ¡líbranos, Señor!».

La interpretación de este motivo debe hacerse, junto a la apreciación que el acto académico le produjese, mediante la lectura de lo que Alonso Zamora Vicente, en La Real Academia Española (1999) ha llamado, en un capítulo imprescindible, «La voz hostil a la Academia», donde traza un recorrido amplio por actitudes que tantas veces significaban un sentimiento de menosprecio, de desconocimiento, de ninguneo por parte de la Academia, y algunas veces problemas reales en tiempos oscuros en los que en la Institución había más políticos que escritores o filólogos.

En el caso de Darío, comenta Zamora: «En 1905, Rubén Darío publica Cantos de vida y esperanza. Ya se ha quedado atrás Prosas profanas (1896): el salto ha sido gigantesco. Basta, para darnos una leve idea del cambio, comparar los versos rubenianos con los vilipendiados por Valbuena en sus Ripios - se refiere Zamora a un episodio trazado previamente como es la obra de Antonio de Valbuena en la que, con el título de Ripios académicos, comenta y analiza versos de Menéndez Pelayo, Alejandro Pidal y Mon, Manuel Cañete, Aureliano Fernández Guerra, José Echegaray, Pedro Madrazo, Manuel Silvela, Juan Valera, Antonio Cánovas del Castillo, Mariano Catalina, Víctor Balaguer, Núñez de Arce, el conde de Cheste- ¡Qué conmoción, la de estos venerables académicos, casi todos vivos en la primera década del siglo Xx, cuando leyeran los poemas de Rubén...! El cervantismo oficial se sentiría sacudido ante la Letanía a nuestro Señor Don Quijote. Y allí se detendrían, inmovilizada la mueca por el estupor, al leer (transcribe los versos 50-55). Quedaba fuera de toda duda que el ruego atañía directamente a numerosos santones consagrados» (Zamora, 1999: 522). 
El contexto que sigue trazando Zamora es el del pleno triunfo de escritores antitéticos a los académicos, como Valle-Inclán (cuya divertida diatriba contra la Academia en Luces de Bohemia es muy conocida), Unamuno, Baroja, Azorín, que tardarían bastantes años en entrar en la Institución. Zamora explica la actitud como una protesta «ante una Academia envejecida».

Es evidente el conjunto de referencias culturales y sociales que el poeta había conseguido establecer en su construcción conmemorativa. Se encerraba en ella no sólo su visión duradera de la obra de Cervantes, sino la visión de la sociedad que vivía aquel centenario.

\section{Bibliografía citada}

Darío, Rubén, Cantos de vida y esperanza. Los cisnes y otros poemas, edición y comentario de José Carlos Rovira, Madrid, Alianza, 2004.

- Don Quijote no debe ni puede morir (Páginas cervantinas), prólogo de Jorge Eduardo Arellano, Managua, Academia Nicaragüense de la Lengua, 2002.

- España contemporánea, Madrid, Mundo Latino, 2017.

- Historia de mis libros; Managua, Editorial Nueva Nicaragua, 1988.

- La vida de Rubén Darío escrita por él mismo, Barcelona, Ediciones G.P., 1959.

- Obra poética, ed. José Carlos Rovira con la colaboración de Sergio Galindo, Madrid, Biblioteca Castro, 2011.

DíEZ DE REVENGA, Francisco Javier, «El cervantismo de Cantos de vida y esperanza», Ínsula, 699, 2005, pp. 15-17.

- «Poesía y mito: la recepción de don Quijote en la lírica de la Edad de Plata», Principe de Viana (Leyendo el Quijote), no 236, sept.-dic. 2005, pp. 713-726,

JiMÉNEZ, Juan Ramón, Mi Rubén Darío, ed. Antonio Sánchez Romeralo, Huelva, Editorial Fundación Juan Ramón Jiménez, 1990.

Mejía, Ernesto, Prólogo a Rubén Darío, Poesía, Caracas, Biblioteca Ayacucho, 1985.

NAVARRo TOMÁs, Tomás, Métrica española, Madrid, Guadarrama, 1974.

ROVIRA, José Carlos, «Rubén Darío: geografía, pintura y paisajes», Centroamericana, vol. 26.2, $2^{\circ}$ semestre 2016, págs..131-157.

SÁNCHEZ, Luis Alberto, «Rubén, fidelísimo lector del Quijote», Seminario Archivo Rubén Darío, Madrid, nº 6, pp. 31-44.

Tercer Centenario del Quijote de la Mancha. <http://biblioteca2.uclm.es/biblioteca/ ceclm/libros/III_centenario/index.htm> [Consulta: 28 mayo 2016].

VALERA/PIDAL, Discurso escrito por encargo de la Real Academia Española para conmemorar el tercer centenario de la publicación de el Ingenioso Hidalgo D. Quijote de la Mancha. Leído por el Excmo. Sr. D. Alejandro Pidal y Mon en la sesión celebrada el día 8 de mayo de 1905 presidida por S. M. el Rey; $<$ http://www.cervantesvirtual.com/obra-visor/discurso-escrito-por-encargode-la-real-academia-espanola-para-conmemorar-el-tercer-centenario-de- 
la-publicacion-de-el-ingenioso-hidalgo-d-quijote-de-la-mancha--0/html/ fef5c0e4-82bl-11df-acc7-002185ce6064_1.html> [Consulta: 30 mayo 2016]. VAlero Juan, Eva, «Del heroísmo hacia el ensueño: en torno a las Páginas cervantinas de Darío en los alrededores culturales del 98», Anales de literatura hispanoamericana, vol. 37, 2008, pp. 143-159.

Zamora Vicente, Alonso, La Real Academia Española, Madrid, Espasa Calpe, 1999. 